\title{
Cadmium Induces Acute Liver Injury by Inhibiting Nrf2 and the Role of NF-KB, NLRP3, and MAPKs Signaling Pathway
}

\author{
Chang Liu ${ }^{1,+}{ }^{-}$, Yaohui Zhu ${ }^{1,+}$, Zhenxiang Lu ${ }^{1}$, Weina Guo ${ }^{1}$, Bayaer Tumen ${ }^{2}$, Yalan He ${ }^{1}$, \\ Chao Chen ${ }^{1}$, Shanshan $\mathrm{Hu}^{1}{ }^{1}$, Kangzhi Xu ${ }^{1}$, Yan Wang ${ }^{1}$, Lei $\mathrm{Li}^{1}{ }^{1, *(D)}$ and Shenghe Li ${ }^{1, *(D)}$ \\ 1 Key Laboratory of Quality \& Safety Control for Pork, Ministry of Agriculture and Rural, College of Animal \\ Science, Anhui Science and Technology University, Fengyang 233100, China; liuchang052@126.com (C.L.); \\ ZYH1823539919@163.com (Y.Z.); luzx@ahstu.edu.cn (Z.L.); guown@ahstu.edu.cn (W.G.); \\ heyalan1996@126.com (Y.H.); ccybtx1@163.com (C.C.); ahkshanshan@163.com (S.H.); \\ 15656202506@163.com (K.X.); wy19940210@sohu.com (Y.W.) \\ 2 Shanxi Animal Disease Control Center, Taiyuan 030027, China; tumengbayaer@163.com \\ * Correspondence: lil@ahstu.edu.cn (L.L.); lish@ahstu.edu.cn (S.L.); Tel.: +86-183-6507-5200 (L.L.); \\ $+86-550-6732-373$ (S.L.) \\ + Equally contributed to this paper.
}

Received: 14 November 2019; Accepted: 20 December 2019; Published: 24 December 2019

\begin{abstract}
Acute Cadmium (Cd) exposure usually induces hepatotoxicity. It is well known that oxidative stress and inflammation causes $\mathrm{Cd}$-induced liver injury. However, the effect of nuclear factor erythroid 2-related factor 2 (Nrf2) in Cd-induced liver injury is not completely understood. In this study, we observed Cd-induced liver damage and the potential contribution of Nrf2, nuclear factor- $\mathrm{KB}$ (NF-kB), Nod-like receptor 3 (NLRP3), and mitogen-activated protein kinases (MAPKs) signaling pathways. Changes in serum transaminases and proinflammatory cytokines expression showed that $\mathrm{Cd}$ could induce acute hepatotoxicity. Moreover, Nrf2 and its downstream heme oxygenase 1 (HO-1) were inhibited by $\mathrm{Cd}$ exposure, and Kelch-like ECH-associated protein 1 (Keap1), the inhibitory protein of Nrf2, was increased. Furthermore, NF-kB, NLRP3, and MAPKs signaling pathways were all activated by $\mathrm{Cd}$ intoxication. In conclusion, the inhibition of $\mathrm{Nrf} 2, \mathrm{HO}-1$, and the activation of NF-KB, NLRP3, and MAPKs all contribute to Cd-induced liver injury.
\end{abstract}

Keywords: Cadmium; acute liver injury; Nrf2; NLRP3; NF-kB; MAPKs

\section{Introduction}

Cadmium (Cd) is a widespread industrial and environmental pollutant, which is has arisen from battery, metals smelting and refining, burning of chemical products, and cigarette smoking. $\mathrm{Cd}$ is also a non-essential element that is found in the human body and that of animals. It can be absorbed into the body through the skin, respiratory passages, and digestive tract. The elimination half-life of $\mathrm{Cd}$ can be as long as 10 to 30 years [1]. Cd exposure can damage a wide variety of tissues, such as liver, kidney, lung, bone, and brain, and also induce immune, nervous, and reproductive system injuries [2-6]. The liver is the largest gland of both the human and animal body and has multiple physiological functions, such as secretion of bile, participation in substance and energy metabolism, phagocytosis, detoxification, and defense. The complexity and diversity of liver function increases the chances of this gland contacting various toxic factors. Therefore, the liver is more vulnerable to pathogenic factors and, consequently, damage. It was reported that the liver is one of the main target tissues in acute or high dose exposure of Cd [7-9]. Cd exposure can also lead to a variety of cancers, especially liver cancer [10]. 
Cd-induced hepatotoxicity mainly involves in two pathways [8]. Firstly, the initial injury, whereby $\mathrm{Cd}$ directly combines with sulfhydryl groups on critical molecules, including glutathione (GSH) and proteins, induces oxidative stress [8]. Second, a subsequent inflammatory injury occurs $[8,11]$. Although $\mathrm{Cd}$ is not a redox reactive metal, its toxicity is mediated via the induction of oxidative stress [11]. Cd binding with sulfhydryl groups results in the generation of reactive oxygen species (ROS) and protein inactivation, and then excessive ROS in turn induces lipid peroxidation and results in DNA damage [12]. The activation of Kupffer cells initiates secondary injury induced by Cd, which results in the production of a large number of proinflammatory cytokines, chemokines, and adhesion molecules to recruit neutrophils to the sites of injury [8]. Kupffer cells and neutrophils both release cytotoxic mediators, including ROS, reactive nitrogen species (RNS), bioactive lipids, and hydrolytic enzymes to cause further liver injuries [13].

Nuclear factor erythroid 2-related factor 2 (Nrf2) is one of the most important transcription factors that initiate a response to oxidative stress. More than $90 \%$ of antioxidative genes are regulated by Nrf2. The inhibition of Nrf2 leads to substantial enrichment of ROS. Nod-like receptor 3 (NLRP3) inflammasome, a multiprotein complex, is the most well explored Nod-like receptor. The activated NLRP3 regulates proinflammatory cytokines maturation, such as interleukin-1 $\beta$ (IL-1 $\beta$ ) and IL-18, resulting in serious inflammatory damage to the liver [14]. Numerous studies showed that ROS is an essential factor for triggering the activation of NLRP3 inflammasome [15-18]. Therefore, the inhibition of Nrf2 activity could enhance the generation of ROS to activate NLRP3 inflammasome-induced inflammation [19-21]. Furthermore, Cd-induced generation of ROS could activate mitogen-activated protein kinases (MAPKs) signaling pathways, leading to cell death [22]. The suppression or inactivation of Nrf2 resulted in the activation of nuclear factor- $\mathrm{KB}(\mathrm{NF}-\mathrm{kB})$ mediated transcriptional activity. A previous study suggested that Cd-induced liver injury was much worse in Nrf2-null mice [23]. Meanwhile, another study reported Cd could induce the activation of NLRP3 inflammasome in vascular endothelial cells [24]. However, the effects of Nrf2 and NLRP3 in Cd-induced liver injury have not been fully elucidated. In the present study, we explored the contribution of Nrf2, NF- $\mathrm{kB}$, NLRP3, and MAPKs in Cd-induced liver injury.

\section{Materials and Methods}

\subsection{Reagents and Antibodies}

$\mathrm{CdCl}_{2}$ was obtained from Shanghai Aladdin Biochemical Technology Co., Ltd. (Shanghai, China), with a purity of $>98.0 \%$. Alanine/aspartate aminotransferase (ALT/AST) kits were obtained from Nanjing Jiancheng Bioengineering Institute (Nanjing, China). T-PER tissue extraction reagent, NE-PER nuclear and cytoplasmic extraction reagents, SuperSignal West Pico PLUS Substrate kit, and Pierce BCA Protein Assay Kit were obtained from ThermoFisher Scientific (Waltham, MA, USA). Murine IL-1 $\beta$ and IL-6 ELISA kits were purchased from Neobioscience (Shenzhen, China). The antibodies that were used for immunoblotting anti-Keap1, -p38, -phospho-p38, -ERK, -phospho-ERK, -JNK, -phospho-JNK, -NLRP3, -NF- KB p65, and -phospho- NF-kB p65 were purchased from Cell Signaling Technology (Danvers, MA, USA) (1:1000 dilutions). The antibodies against Nrf2 and HO-1 were all purchased from Santa Cruz (Santa Cruz, CA, USA) (all 1:200 dilutions). Antibodies against GAPDH were purchased from Abways Technology (Shanghai, China) (1:2000 dilutions). Peroxidase-conjugated goat anti-rabbit immunoglobulin $\operatorname{IgG}(\mathrm{H}+\mathrm{L})$, anti-mouse $\operatorname{IgG}(\mathrm{H}+\mathrm{L})$, and anti-goat $\operatorname{IgG}(\mathrm{H}+\mathrm{L})$ were obtained from Proteintech Group (Wuhan, China). Other reagents, unless indicated, were obtained from Sigma Chemical Co. (St. Louis, MO, USA).

\subsection{Animals and Treatments}

Specific pathogen-free male ICR mice ( $20 \pm 2 \mathrm{~g}$ body weight) were obtained from the Qinglongshan Laboratory Animal Center (Nanjing, China). The mice were fed with a standard laboratory diet and ample water at room temperature with a $12 \mathrm{~h}$ light-dark cycle with $60 \pm 10 \%$ humidity. All of the 
animals received humane care in line with the institutional animal care guidelines that the Experimental Animal Ethical Committee, Anhui Science and Technology University approved (No.008, Approval date: 25 February 2019).

The mice were randomly separated into two groups: (1) Vehicle control (intraperitoneal injection of saline $0.1 \mathrm{~mL} / 10 \mathrm{~g}, n=8)$, or (2) $\mathrm{CdCl}_{2}(4 \mathrm{mg} / \mathrm{kg}, n=40)$, animals were sacrificed after $3 \mathrm{~h}, 6 \mathrm{~h}, 12 \mathrm{~h}$, $18 \mathrm{~h}$, and $24 \mathrm{~h} \mathrm{CdCl}_{2}$ intoxication (eight mice at each time point), then the samples of plasma and liver tissue were collected and stored at $-80{ }^{\circ} \mathrm{C}$ for further analysis.

\subsection{Analysis of Serum ALT/AST Activities}

The blood samples were collected and then kept at room temperature for $2 \mathrm{~h}$. Serum was harvested after centrifugation at $1500 \times g$ for $10 \mathrm{~min}$. Serum ALT/AST were measured with kits according to the manufacturer's protocol.

\subsection{ELISA Assay}

The concentrations of IL-1 $\beta$ and IL- 6 in serum were measured with commercial ELISA kits while referring to the manufacturer's protocols.

\subsection{Liver Histological Analysis}

Tissue slices harvested from the same location within the liver in mice were fixed in $10 \%$ phosphate buffered saline-formalin for at least $24 \mathrm{~h}$ and all the samples were dehydrated, and then embedded in paraffin for histological check of liver tissue damage. The samples were subsequently sectioned at $5 \mu \mathrm{m}$, and then stained with hematoxylin and eosin (H\&E) to appraise liver injury.

\subsection{Western Blot Analysis}

The liver tissue cellular proteins were extracted by using T-PER tissue extraction reagent or NE-PER nuclear and cytoplasmic extraction reagents according to the manufacturer's protocols. Equal amounts of protein from each sample was separated by 10\% SDS-PAGE gel and then transferred to PVDF membrane. After $1 \mathrm{~h}$ blocking with 5\% BSA at room temperature, the membranes were incubated with primary antibodies at $4{ }^{\circ} \mathrm{C}$ overnight. Subsequently, membranes were probed with horseradish peroxidase-conjugated secondary antibodies at room temperature for $1 \mathrm{~h}$. After washing three times with tris-buffered saline-tween (TBST), the membranes were visualized by SuperSignal West Pico PLUS Substrate kit.

\subsection{Statistical Analysis}

The data were expressed as means \pm standard error of mean (SEM). Multiple comparisons among different groups were conducted by one-way analysis of variance (ANOVA) with Dunnett's post-test, and SPSS 23.0 analyzed all data. $p<0.05$ was defined as a statistically significant difference.

\section{Results}

\subsection{Cadmium Increases the Activities of ALT/AST}

Serum ALT and AST level were measured to evaluate Cd-induced liver injury. As shown in Figure 1, when compared to the control group, the serum ALT level significantly increased after Cd exposure for $12 \mathrm{~h}$ and AST level increased significantly after Cd exposure for $6 \mathrm{~h}$, and both ALT and AST concentrations were highest after Cd exposure for $18 \mathrm{~h}$. However, the concentrations of ALT and AST were decreased after Cd exposure for $24 \mathrm{~h}$ as compared to $18 \mathrm{~h}$. The results indicated acute $\mathrm{Cd}$ intoxication, resulting in liver injury after $\mathrm{Cd}$ exposure for $6 \mathrm{~h}$, and damaged liver tissue was gradually recovered after $18 \mathrm{~h}$. 

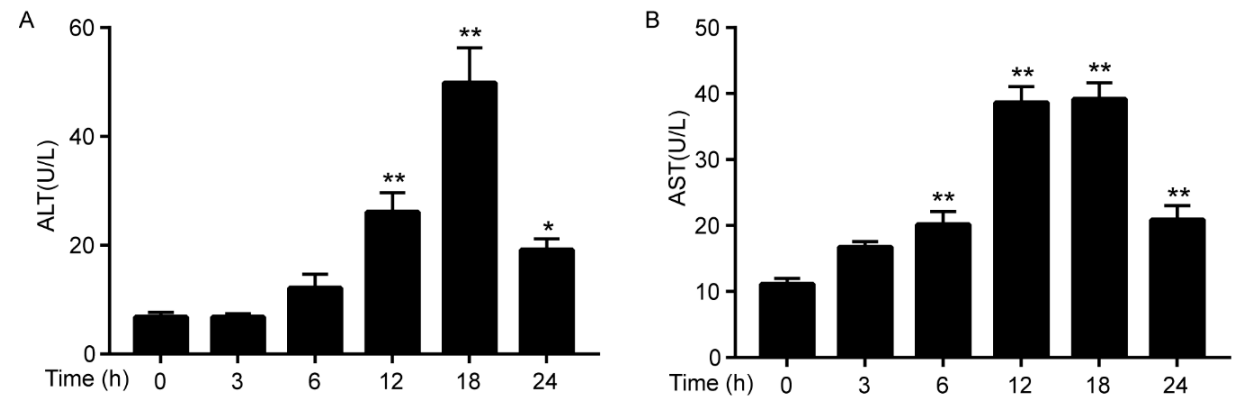

Figure 1. Cd-induced elevated serum Alanine (ALT) (A) and aspartate aminotransferase (AST) (B) activities in mice. Data were expressed as means \pm SEM $(n=8)$. ${ }^{*} p<0.05,{ }^{* *} p<0.01$ compared to control.

\subsection{Cadmium Induces Pro-Inflammatory Cytokines Expression in Serum}

Secondary inflammation plays a vital contribution on Cd-induced liver injury; therefore, ELISAs evaluated proinflammatory cytokines. As shown in Figure $2 A, B$, the concentration of IL-1 $\beta$ and IL-6 were elevated at all time intervals examined, and the concentrations of the cytokines were greatest after $6 \mathrm{~h}$ of $\mathrm{Cd}$ intoxication.
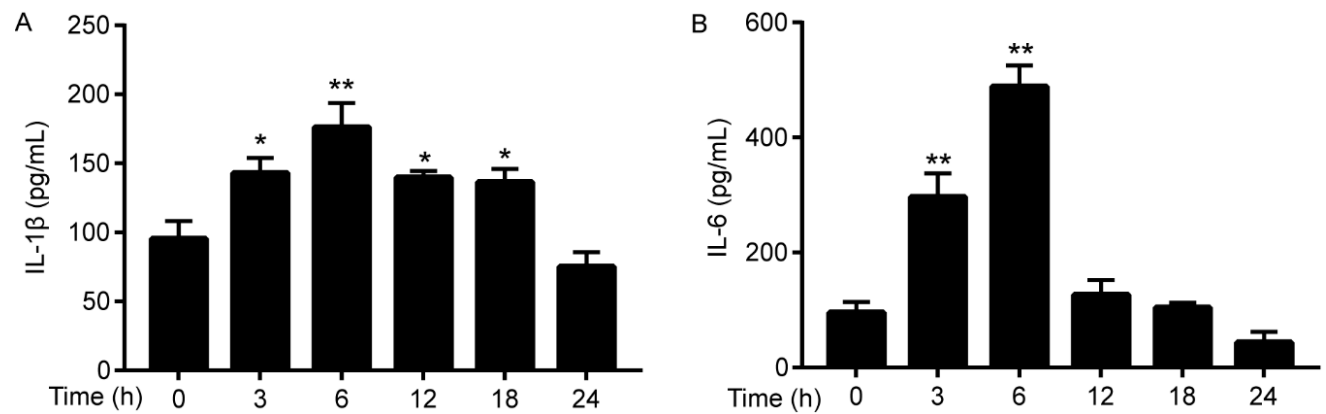

Figure 2. Cd-induced increase in serum inflammatory cytokines IL-1 $\beta$ (A) and IL-6 (B) in mice. Data were expressed as means $\pm \operatorname{SEM}(n=8) .{ }^{*} p<0.05,{ }^{* *} p<0.01$ compared to control.

\subsection{Cadmium Induces Histopathological Changes}

Histopathological examination of liver tissue was used to assess $\mathrm{Cd}$ induced hepatotoxicity. After $\mathrm{Cd}$ exposure for $18 \mathrm{~h}$, the liver tissue showed extensive necrosis and neutrophil infiltration, as shown in Figure 3.
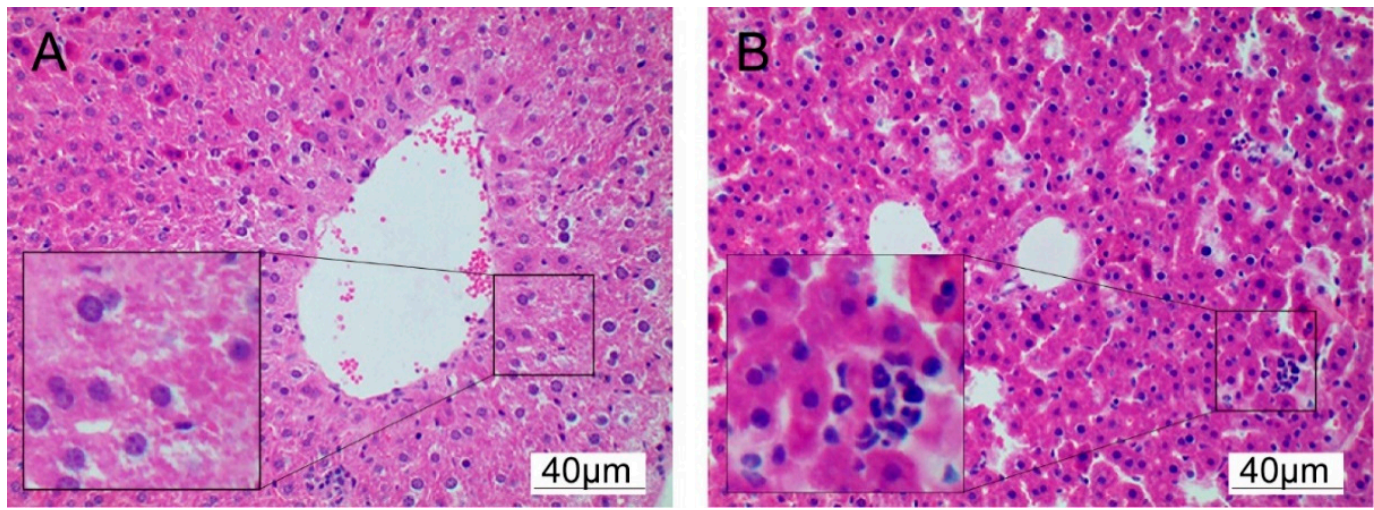

Figure 3. Histological observation of $\mathrm{Cd}$-induced liver injury of mice. After $\mathrm{Cd}$ exposure for $18 \mathrm{~h}$, the liver was collected for section and processing for H\&E staining $(n=3)$. (A) Control, (B) Cd (4 mg/kg) $18 \mathrm{~h}$ (magnification $\times 200$ ). 


\subsection{Cadmium Treatment Results in Nrf2 Inhibition in Liver}

Nuclear translocation is an essential indicator of Nrf2 activation; therefore western blotting was used to determine the activation of Nrf2. As shown in Figure 4, compared to control group, nuclear translocation was inhibited after $\mathrm{CdCl}_{2}$ challenge. Meanwhile, Keap1, which is a negative regulator of $\mathrm{Nrf2}$, was significantly upregulated by $\mathrm{CdCl}_{2}$ exposure. Besides, $\mathrm{CdCl} 2$ also markedly decreased Nrf2-regulated antioxidative enzyme HO-1. However, $\mathrm{Cd}$ has no obvious effect on the expression of p62.
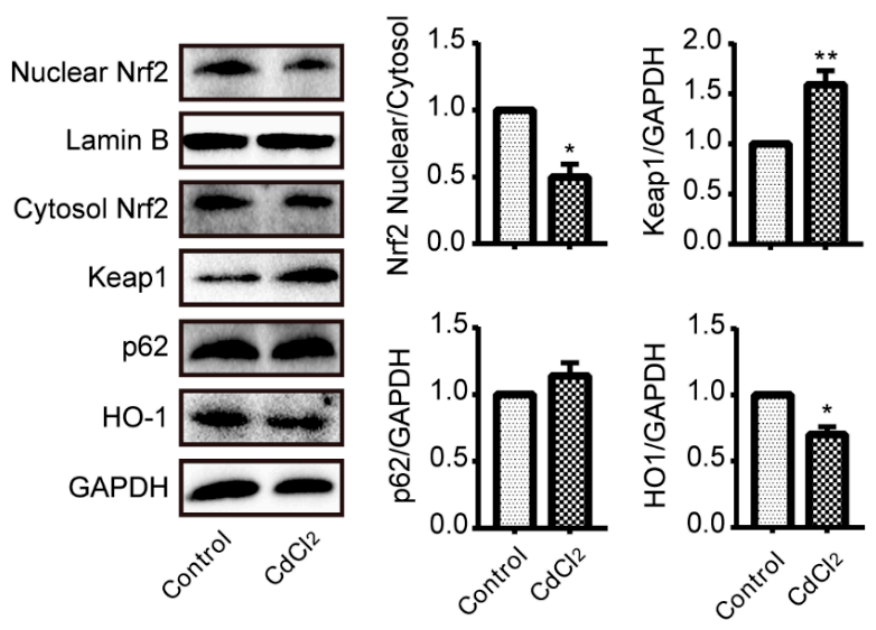

Figure 4. Cd inhibited Nrf2 signaling pathway in mouse liver $(n=4)$. Western blotting analysis of Nrf2, Keap1, p62 and HO-1. The density of the western blotting was normalized for GAPDH/Lamin B. ${ }^{*} p<0.05,{ }^{* *} p<0.01$ as compared to control.

\subsection{Cadmium Treatment Results in NF- $\kappa B$ p65, NLRP3, and MAPKs Activation in Liver}

The phosphorylation of p65 subunit plays a key role in regulating NF- $\mathrm{kB}$ activation. Therefore, we detected phosphorylated-p65 by western blotting. Phosphorylation of p65 was increased after $\mathrm{CdCl}_{2}$ exposure, as shown in Figure 5. NLRP3 is also a critical molecular in inflammatory injury, thus we evaluated the expression of NLRP3 by western blotting. It was upregulated in the liver when the mice were intoxicated by $\mathrm{CdCl}_{2}$. MAPKs is a family of serine/threonine kinases, which are involved in signal transduction pathways that control proliferation, gene expression, differentiation, inflammation, cell survival, and apoptosis [25]. Phosphorylation is required for MAPKs activation, and the results in Figure 5 showed a significant activation of ERK, JNK, and p38. 

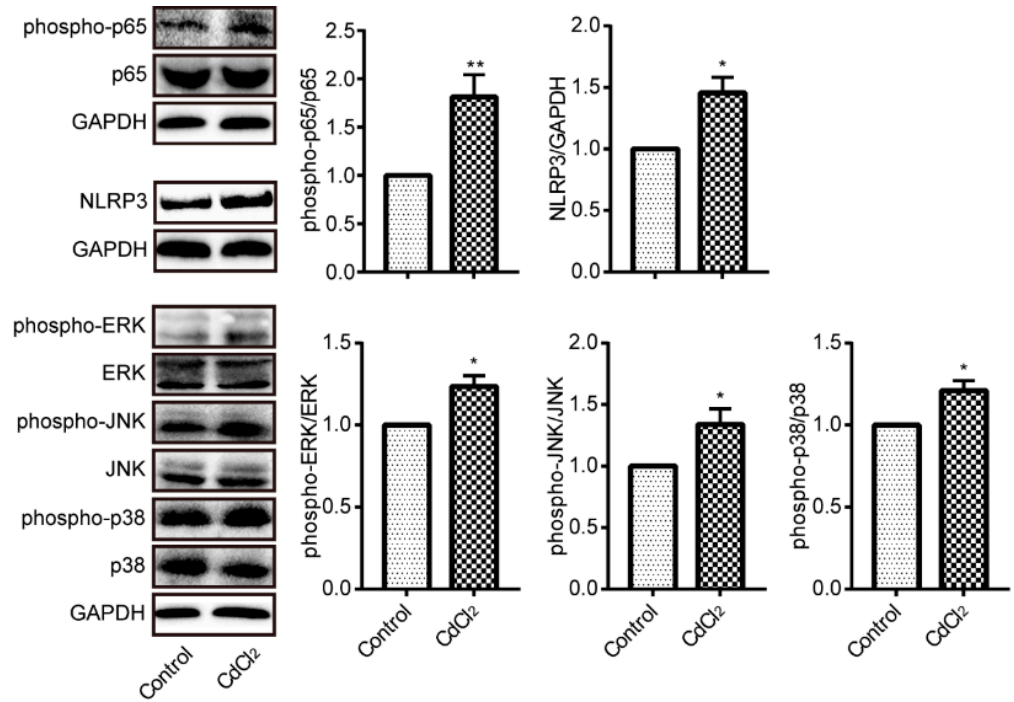

Figure 5. Cd activated nuclear factor- $\mathrm{kB}(\mathrm{NF}-\mathrm{kB})$, Nod-like receptor 3 (NLRP3), and mitogen-activated protein kinases (MAPKs) in mouse liver $(n=4)$. Phosphorylation of p65, ERK, JNK and p38 and the expression of NLRP3 were evaluated by Western blotting. ${ }^{*} p<0.05,{ }^{* *} p<0.01$ compared to control.

\section{Discussion}

The present study demonstrated that $\mathrm{Cd}$ exposure significantly damaged mice liver. Firstly, the serum ALT/AST were elevated after Cd treatment, and inflammatory injury was also observed by increased proinflammatory cytokines. Furthermore, Keap1/Nrf2 antioxidative signaling pathway was inhibited and simultaneously proinflammatory signaling pathways of NLRP3, NF- $\mathrm{KB}$, and MAPKs were activated as a result of $C d$ exposure in mice liver.

In the present study, serum ALT/AST activities reached a summit after $18 \mathrm{~h}$ of Cd intoxicant, indicating acute liver damage; meanwhile, oxidative stress was considered as the initial stimulation of Cd-induced liver injury [8]. Therefore, we choose the $18 \mathrm{~h}$ as the time point to measure the activation of Nrf2, which is essential in regulating the expression of antioxidative genes, such as HO-1. As the most important transcription factor in regulating antioxidative genes, Nrf2 was activated when it translocates into the nucleus, heterodimerizes with small Maf preteins, and then binds to the ARE sequence [26], which is known as canonical mechanisms of Nrf2 activation [27]. Our results showed that the expression of $\mathrm{Nrf2}$ in nuclear was decreased after $\mathrm{Cd}$ exposure, which is indicative of the inhibition of Nrf2. HO-1, an antioxidative enzyme, which is the downstream of Nrf2, was also suppressed. Keap1, as an adapter subunit of Cullin3-based-E3 ubiquitin ligase, is a negative regulator of Nrf2, which regulates the degradation of Nrf2 [28]. Our data demonstrated that the expression of Keap1 was increased by Cd treatment. The p62, which is another regulator of Nrf2, is involved in non-canonical mechanisms of Nrf2 activation [27]. The role of p62 is mainly sequestering Keap1 to autophagic degradation that ultimately results in the stabilization of Nrf2 [28,29]. However, Cd exposure had no effect on the expression of p62. Taken together, increasing the expression of Keap1 results in the inhibition of Nrf2, which contributes to Cd-induced oxidative injury and they are in line with previous findings $[23,30]$.

$\mathrm{NF}-\mathrm{kB}$, another protein complex, is a redox-sensitive transcription factor that is involved in the transcription of proinflammatory cytokines. It is well known that excessive ROS can activate the transcription of NF- $\mathrm{kB}$ resulting in overproduction of proinflammatory mediators. A previous study demonstrated that inhibition of Nrf2 showed more prominent activation of NF- $\mathrm{kB}$, which is mediated by activation of inhibitor of nuclear factor $\kappa B$ kinase (IKK) and the degradation of NF- $\kappa B$ inhibitor $\alpha(\mathrm{I} \kappa \mathrm{B}-\alpha)$ [31]. Moreover, the activity of NF- $\mathrm{kB}$ p65 subunit also regulates Nrf2 induced antioxidant responsive element (ARE)-linked gene expression [32]. Firstly, increased p65 could promote Keap1 nuclear translocation, which could abrogate Nrf2-ARE signaling [33]. Moreover, phosphorylated 
p65 displays a preference of binding to CREB-binding protein (CBP), a transcriptional co-activator for Nrf2, which results in limited formation of CBP-Nrf2 complex [23,28,29]. In addition, p65 could prevent Nrf2 heterodimer formation leading to decrease of ARE-mediated gene expression [32,34]. Our results showed that phosphorylated p65 subunit was enhanced and Nrf2-regulated HO-1 expression was particularly decreased in Cd-treated mice liver, which might reveal that the activation of NF- $\mathrm{KB}$ contribute to Cd-induced Nrf2 inactivation.

Inflammation was considered as the subsequent injury for Cd-induced hepatotoxicity. NLRP3 inflammasome facilitates a wide range of microbial and oxidative stress responses, and it mediates the cleavage of caspase- 1 and the secretion of the proinflammatory cytokine IL-1 $\beta$, which could induce serious inflammation. Inhibition of Nrf2 leads to overproduce of ROS, which is an essential factor in NLRP3 activation. In the present study, we found NLRP3 was elevated by Cd exposure, which might be relative with suppression of $\mathrm{Nrf2}$ and it is consistent with previous reports [24,35].

MAPKs, which are mainly composed of ERK, JNK, and p38, are critical for regulating oxidative and inflammatory damages. It is well studied that oxidative stress induces phosphorylation of JNK, ERK, and p38 in different cell types [36]. Cd-induced oxidative stress could stimulate MAPKs in different situations. It was reported that Cd could activate ERK, JNK, and p38 in neuronal PC21 and SH-SY5Y cells $[37,38]$. However, only ERK and JNK were activated in Cd-treated human renal endothelial cells [39]. Another study showed ERK was the major pathway involved in Cd-treated prostate epithelial cells [40]. Moreover, Zou et al. [41] reported that Cd treatment resulted in the activation of MAPKs, while ERK and p38 inhibitors, but not JNK inhibitor, attenuated Cd-induced hepatotoxicity. In this study, we found that ERK, JNK, and p38 were all activated by Cd, which contributes to Cd-induced hepatotoxicity. Therefore, the findings revealed that Cd-induced MAPKs activation is likely to be specific to the cell type and dose tested. Furthermore, the MAPKs are implicated to be able to activate IKK to induce NF- $K B$ nucleus translocation and activate gene transcription [42], which suggested that Cd-induced MAPKs activation might be contribute to Cd-induced NF- $\mathrm{KB}$ activation.

\section{Conclusions}

The results of our study suggest that the suppression of Nrf2 and its downstream HO-1 greatly contributed to Cd-induced acute liver injury, and NF- $\mathrm{BB}, \mathrm{NLRP3}$, and MAPKs were all involved in Cd-induced hepatotoxicity. Nrf2, NF-kB, NLRP3 and MAPKs may be therapy targets for amelioration of $\mathrm{Cd}$-induced liver damage. However, numerous signaling pathways are involved in the regulation of Nrf2 activation, including canonical and non-canonical mechanisms of Nrf2 activation; therefore, more investigation should be explored in the Cd-regulated Nrf2 signaling pathway.

Author Contributions: Experimental design, L.L., C.L.; Investigation, C.L., Y.Z., Y.H., C.C., S.H., K.X., Y.W.; data analysis, Y.Z., L.L.; writing-original draft preparation, C.L., Y.Z., L.L.; writing-review and editing, C.L., Z.L., W.G., B.T., L.L., S.L.; funding acquisition, L.L., S.L. All authors have read and agreed to the published version of the manuscript.

Funding: This research was funded by National Natural Science Foundation of China (31802242), Young Talents Visiting and Training Program for Foreign Country of Anhui Education Department (gxgwfx2019047), Natural Science Key Foundation of Anhui Education Department (KJ2017A503, KJ2017A504), Talent Project of Anhui Science and Technology University (ZRC2014447), Leading Academic Discipline Project of Anhui Science and Technology University (AKZDXK2015A04), and College Students' Innovative Training Program of Anhui Province (2018S10879013).

Acknowledgments: The authors greatly thank Debbie Nash, Institute of Biological, Environmental and Rural Sciences, Aberystwyth University, UK, for language editing and suggestions.

Conflicts of Interest: The authors declare no conflict of interest. 


\section{References}

1. Nordberg, G.F.; Kjellstrom, T. Metabolic model for cadmium in man. Environ. Health Perspect 1979, 28, 211-217. [CrossRef] [PubMed]

2. Hosohata, K.; Mise, N.; Kayama, F.; Iwanaga, K. Augmentation of cadmium-induced oxidative cytotoxicity by pioglitazone in renal tubular epithelial cells. Toxicol. Ind. Health 2019, 35, 530-536. [CrossRef] [PubMed]

3. Mezynska, M.; Brzoska, M.M. Environmental exposure to cadmium-a risk for health of the general population in industrialized countries and preventive strategies. Environ. Sci. Pollut. Res. Int. 2018, 25, 3211-3232. [CrossRef] [PubMed]

4. Nawrot, T.S.; Staessen, J.A.; Roels, H.A.; Munters, E.; Cuypers, A.; Richart, T.; Ruttens, A.; Smeets, K.; Clijsters, H.; Vangronsveld, J. Cadmium exposure in the population: From health risks to strategies of prevention. Biometals 2010, 23, 769-782. [CrossRef] [PubMed]

5. Nordberg, M.; Nordberg, G.F. Toxicological aspects of metallothionein. Cell. Mol. Biol. 2000, 46, 451-463.

6. Saedi, S.; Jafarzadeh, S.M.; Totonchi, M.; Zamiri, M.J.; Derakhshanfar, A. Effect of Prepubertal Exposure to $\mathrm{CdCl}_{2}$ on the Liver, Hematological, and Biochemical Parameters in Female Rats; an Experimental Study. Biol. Trace Elem. Res. 2019. [CrossRef]

7. Mezynska, M.; Brzoska, M.M. Review of polyphenol-rich products as potential protective and therapeutic factors against cadmium hepatotoxicity. J. Appl. Toxicol. 2019, 39, 117-145. [CrossRef]

8. Rikans, L.E.; Yamano, T. Mechanisms of cadmium-mediated acute hepatotoxicity. J. Biochem. Mol. Toxicol. 2000, 14, 110-117. [CrossRef]

9. Andjelkovic, M.; Buha, D.A.; Antonijevic, E.; Antonijevic, B.; Stanic, M.; Kotur-Stevuljevic, J.; Spasojevic-Kalimanovska, V.; Jovanovic, M.; Boricic, N.; Wallace, D.; et al. Toxic Effect of Acute Cadmium and Lead Exposure in Rat Blood, Liver, and Kidney. Int. J. Environ. Res. Public Health 2019, 16, 274. [CrossRef]

10. Ledda, C.; Loreto, C.; Zammit, C.; Marconi, A.; Fago, L.; Matera, S.; Costanzo, V.; Fuccio, S.G.; Palmucci, S.; Ferrante, M.; et al. Noninfective occupational risk factors for hepatocellular carcinoma: A review (Review). Mol. Med. Rep. 2017, 15, 511-533. [CrossRef]

11. Salama, S.A.; Arab, H.H.; Hassan, M.H.; Al, R.M.; Maghrabi, I.A. Cadmium-induced hepatocellular injury: Modulatory effects of gamma-glutamyl cysteine on the biomarkers of inflammation, DNA damage, and apoptotic cell death. J. Trace Elem. Med. Biol. 2019, 52, 74-82. [CrossRef] [PubMed]

12. Hassoun, E.A.; Stohs, S.J. Cadmium-induced production of superoxide anion and nitric oxide, DNA single strand breaks and lactate dehydrogenase leakage in J774A.1 cell cultures. Toxicology 1996, 112, 219-226. [CrossRef]

13. Yamano, T.; DeCicco, L.A.; Rikans, L.E. Attenuation of cadmium-induced liver injury in senescent male fischer 344 rats: Role of Kupffer cells and inflammatory cytokines. Toxicol. Appl. Pharmacol. 2000, 162, 68-75. [CrossRef] [PubMed]

14. Wree, A.; Eguchi, A.; McGeough, M.D.; Pena, C.A.; Johnson, C.D.; Canbay, A.; Hoffman, H.M.; Feldstein, A.E. NLRP3 inflammasome activation results in hepatocyte pyroptosis, liver inflammation, and fibrosis in mice. Hepatology 2014, 59, 898-910. [CrossRef] [PubMed]

15. Heid, M.E.; Keyel, P.A.; Kamga, C.; Shiva, S.; Watkins, S.C.; Salter, R.D. Mitochondrial reactive oxygen species induces NLRP3-dependent lysosomal damage and inflammasome activation. J. Immunol. 2013, 191, 5230-5238. [CrossRef] [PubMed]

16. Sorbara, M.T.; Girardin, S.E. Mitochondrial ROS fuel the inflammasome. Cell Res. 2011, 21, 558-560. [CrossRef]

17. Zhou, R.; Yazdi, A.S.; Menu, P.; Tschopp, J. A role for mitochondria in NLRP3 inflammasome activation. Nature 2011, 469, 221-225. [CrossRef]

18. Jo, E.K.; Kim, J.K.; Shin, D.M.; Sasakawa, C. Molecular mechanisms regulating NLRP3 inflammasome activation. Cell. Mol. Immunol. 2016, 13, 148-159. [CrossRef]

19. Liu, X.; Zhang, X.; Ding, Y.; Zhou, W.; Tao, L.; Lu, P.; Wang, Y.; Hu, R. Nuclear Factor E2-Related Factor-2 Negatively Regulates NLRP3 Inflammasome Activity by Inhibiting Reactive Oxygen Species-Induced NLRP3 Priming. Antioxid. Redox Signal. 2017, 26, 28-43. [CrossRef] 
20. Rzepecka, J.; Pineda, M.A.; Al-Riyami, L.; Rodgers, D.T.; Huggan, J.K.; Lumb, F.E.; Khalaf, A.I.; Meakin, P.J.; Corbet, M.; Ashford, M.L.; et al. Prophylactic and therapeutic treatment with a synthetic analogue of a parasitic worm product prevents experimental arthritis and inhibits IL-1beta production via NRF2-mediated counter-regulation of the inflammasome. J. Autoimmun. 2015, 60, 59-73. [CrossRef]

21. Xu, X.; Zhang, L.; Ye, X.; Hao, Q.; Zhang, T.; Cui, G.; Yu, M. Nrf2/ARE pathway inhibits ROS-induced NLRP3 inflammasome activation in BV2 cells after cerebral ischemia reperfusion. Inflamm. Res. 2018, 67, 57-65. [CrossRef] [PubMed]

22. Xu, B.; Chen, S.; Luo, Y.; Chen, Z.; Liu, L.; Zhou, H.; Chen, W.; Shen, T.; Han, X.; Chen, L.; et al. Calcium signaling is involved in cadmium-induced neuronal apoptosis via induction of reactive oxygen species and activation of MAPK/mTOR network. PLoS ONE 2011, 6, e19052. [CrossRef] [PubMed]

23. Wu, K.C.; Liu, J.J.; Klaassen, C.D. Nrf2 activation prevents cadmium-induced acute liver injury. Toxicol. Appl. Pharmacol. 2012, 263, 14-20. [CrossRef] [PubMed]

24. Chen, H.; Lu, Y.; Cao, Z.; Ma, Q.; Pi, H.; Fang, Y.; Yu, Z.; Hu, H.; Zhou, Z. Cadmium induces NLRP3 inflammasome-dependent pyroptosis in vascular endothelial cells. Toxicol. Lett. 2016, 246, 7-16. [CrossRef] [PubMed]

25. Pearson, G.; Robinson, F.; Beers, G.T.; Xu, B.E.; Karandikar, M.; Berman, K.; Cobb, M.H. Mitogen-activated protein (MAP) kinase pathways: Regulation and physiological functions. Endocr. Rev. 2001, 22, 153-183. [PubMed]

26. Li, W.; Yu, S.; Liu, T.; Kim, J.H.; Blank, V.; Li, H.; Kong, A.N. Heterodimerization with small Maf proteins enhances nuclear retention of Nrf2 via masking the NESzip motif. Biochim. Biophys. Acta 2008, 1783, 1847-1856. [CrossRef]

27. Silva-Islas, C.A.; Maldonado, P.D. Canonical and non-canonical mechanisms of Nrf2 activation. Pharmacol. Res. 2018, 134, 92-99. [CrossRef]

28. Ahmed, S.M.; Luo, L.; Namani, A.; Wang, X.J.; Tang, X. Nrf2 signaling pathway: Pivotal roles in inflammation. Biochim. Biophys. Acta Mol. Basis Dis. 2017, 1863, 585-597. [CrossRef]

29. Komatsu, M.; Kurokawa, H.; Waguri, S.; Taguchi, K.; Kobayashi, A.; Ichimura, Y.; Sou, Y.S.; Ueno, I.; Sakamoto, A.; Tong, K.I.; et al. The selective autophagy substrate p62 activates the stress responsive transcription factor Nrf2 through inactivation of Keap1. Nat. Cell Biol. 2010, 12, 213-223. [CrossRef]

30. Almeer, R.S.; AlBasher, G.I.; Alarifi, S.; Alkahtani, S.; Ali, D.; Abdel, M.A. Royal jelly attenuates cadmium-induced nephrotoxicity in male mice. Sci. Rep. 2019, 9, 5825. [CrossRef]

31. Cho, H.Y.; Imani, F.; Miller-DeGraff, L.; Walters, D.; Melendi, G.A.; Yamamoto, M.; Polack, F.P.; Kleeberger, S.R. Antiviral activity of Nrf2 in a murine model of respiratory syncytial virus disease. Am. J. Respir. Crit. Care Med. 2009, 179, 138-150. [CrossRef] [PubMed]

32. Wardyn, J.D.; Ponsford, A.H.; Sanderson, C.M. Dissecting molecular cross-talk between Nrf2 and NF-kappaB response pathways. Biochem. Soc. Trans. 2015, 43, 621-626. [CrossRef] [PubMed]

33. Yu, M.; Li, H.; Liu, Q.; Liu, F.; Tang, L.; Li, C.; Yuan, Y.; Zhan, Y.; Xu, W.; Li, W.; et al. Nuclear factor p65 interacts with Keap1 to repress the Nrf2-ARE pathway. Cell. Signal. 2011, 23, 883-892. [CrossRef] [PubMed]

34. Liu, G.H.; Qu, J.; Shen, X. NF-kappaB/p65 antagonizes Nrf2-ARE pathway by depriving CBP from Nrf2 and facilitating recruitment of HDAC3 to MafK. Biochim. Biophys. Acta 2008, 1783, 713-727. [CrossRef] [PubMed]

35. Cao, Z.; Fang, Y.; Lu, Y.; Tan, D.; Du, C.; Li, Y.; Ma, Q.; Yu, J.; Chen, M.; Zhou, C.; et al. Melatonin alleviates cadmium-induced liver injury by inhibiting the TXNIP-NLRP3 inflammasome. J. Pineal Res. 2017, 62, e12389. [CrossRef] [PubMed]

36. Mitchell, C.; Joyce, A.R.; Piper, J.T.; McKallip, R.J.; Fariss, M.W. Role of oxidative stress and MAPK signaling in reference moist smokeless tobacco-induced HOK-16B cell death. Toxicol. Lett. 2010, 195, 23-30. [CrossRef]

37. Chen, L.; Liu, L.; Huang, S. Cadmium activates the mitogen-activated protein kinase (MAPK) pathway via induction of reactive oxygen species and inhibition of protein phosphatases 2A and 5. Free Radic. Biol. Med. 2008, 45, 1035-1044. [CrossRef]

38. Kalariya, N.M.; Wills, N.K.; Ramana, K.V.; Srivastava, S.K.; van Kuijk, F.J. Cadmium-induced apoptotic death of human retinal pigment epithelial cells is mediated by MAPK pathway. Exp. Eye Res. 2009, 89, 494-502. [CrossRef]

39. Rajendran, P.; Rengarajan, T.; Nishigaki, Y.; Palaniswami, R.; Nishigaki, I. In vitro studies on mangiferin protection against cadmium-induced human renal endothelial damage and cell death via the MAP kinase and NF-kappaB pathways. J. Recept. Signal. Transduct. Res. 2016, 36, 57-66. [CrossRef] 
40. Dasgupta, P.; Kulkarni, P.; Bhat, N.S.; Gupta, R.; Hashimoto, Y.; Saini, S.; Dar, A.A.; Shahryari, V.; Yamamura, S.; Tanaka, Y.; et al. Abstract 4659: Cadmium induced malignant transformation involves activation of the Erk/MAPK pathway. Cancer Res. 2019, 79, 4659.

41. Zou, H.; Liu, X.; Han, T.; Hu, D.; Wang, Y.; Yuan, Y.; Gu, J.; Bian, J.; Zhu, J.; Liu, Z.P. Salidroside Protects against Cadmium-Induced Hepatotoxicity in Rats via GJIC and MAPK Pathways. PLoS ONE 2015, 10, e129788. [CrossRef] [PubMed]

42. Nemmiche, S. Oxidative Signaling Response to Cadmium Exposure. Toxicol. Sci. 2017, 156, 4-10. [CrossRef] [PubMed]

(C) 2019 by the authors. Licensee MDPI, Basel, Switzerland. This article is an open access article distributed under the terms and conditions of the Creative Commons Attribution (CC BY) license (http://creativecommons.org/licenses/by/4.0/). 